\title{
Persepsi Guru Tentang Pelaksanaan Pembelajaran Blended Learning Ditengah Pandemi Covid-19
}

\author{
Alfina Zaharra ${ }^{1}$ dan Wagino ${ }^{1 *}$ \\ ${ }^{1}$ Teknik Otomotif, Fakultas Teknik, Universitas Negeri Padang \\ Jln. Prof. Dr. Hamka Air Tawar Padang 25131 INDONESIA \\ *e-mail:alfinazaharra7@gmail.com, wagino5520@gmail.com \\ (Diajukan: 04 Maret 2021, direvisi:21 April 2021, disetujui: 26 April 2021)
}

\begin{abstract}
Abstrak
Salah satu efek dari situasi pandemi covid-19 adalah penerapan model pembelajaran blended learning pada bidang pendidikan. Penelitian ini bertujuan untuk melihat bagaimana persepsi guru tentang pelaksanaan pembelajaran blended learning yang baru dilaksanakan ditengah pandemi covid-19 di SMK Negeri 1 Padang dari faktor model pembelajaran, metode pembelajaran, dan media pembelajaran. Jenis penelitian ini adalah deskriptif kuantitatif dengan populasi penelitian adalah 90 orang guru dan sampel penelitian 47 guru. Pengumpulan data menggunakan kuesioner dengan Skala Likert. Hasil penelitian ini menunjukan : 1) model pembelajaran blended learning berada pada kategori baik dengan tingkat capaian skor 4,35. 2) metode pembelajaran blended learning berada pada kategori baik dengan tingkat capaian skor 4,36. 3) media pembelajaran blended learning berada pada kategori baik dengan tingkat capaian skor 4,52. Dengan demikian dapat disimpulkan bahwa persepsi guru tentang pelaksanaan pembelajaran Blended Learning ditengah pandemi Covid19 di SMK Negeri 1 Padang berada pada kategori baik dengan tingkat capaian skor sebesar 4,41 .
\end{abstract}

Kata Kunci: Covid-19, persepsi guru, blended learning

\begin{abstract}
One of the effects of the Covid-19 pandemic situation is the application of the Blanded learning model in education. Tthis research aims to see how teachers' perceptions of the implementation of blended learning that have just been implemented in the midst of the Covid-19 pandemic at SMK Negeri 1 Padang from the learning model factor., learning methods, and learning media. This type of research is descriptive quantitative. The study population was 90 teachers and the research sample was 47 teachers. Collecting data using a questionnaire with a Likert scale. The results of this study indicate: 1) the blended learning model is in a good category with a score of 4.35.2) the blended learning method is in the good category with a score of 4.36. 3) the blended learning media is in a good category with a score of 4.52. Thus it can be concluded that the Teacher's Perception of the Implementation of Blended Learning in the Middle of the Covid-19 Pandemic at SMK Negeri 1 Padang is in the good category with an achievement level of a score of 4.41 .
\end{abstract}

Keywords: Covid-19, teacher perception, blended learning 


\section{PENDAHULUAN}

Pendidikan merupakan salah satu bidang yang dipermudah dengan adanya teknologi dan informasi terutama dalam proses pembelajaran. Pada kegiatan pembelajaran umumnya dilakukan secara langsung di dalam ruang kelas, yaitu guru dan siswa berinteraksi secara langsung. Namun saat terjadinya pandemi covid-19 pembelajaran dilakukan secara daring/dalam jaringan. Suatu penyebab terjadinya perubahan besar tersebut dalam proses belajar daring yang dilaksanankan dengan cara dadakan, yang berdampak besar terhadap persiapan siswa, guru dan sekolah untuk melakukan proses belajar daring. Pelaksanaan pembelajran daring tentunya memiliki banyak kendala, berdasarkan hasil wawancara yang dilakukan peneliti dengan beberapa guru di SMKN 1 Padang bahwa pembelajaran daring masih jauh dari tujuan dalam pembelajaran, guru dan siswa yang belum terbiasa melakukan proses pembelajaran secara daring. Siswa mulai merasa jenuh dengan pembelajaran daring, pembelajaran teori hanya mencapai $40 \%$ sedangkan pratikum hanya mencapai $10 \%$, untuk mengatasi permasalahan tersebut saat ini SMK N 1 padang mernerapkan model pembelajaran blended learning. Karena model pembelajaran ini baru diterapkan maka terdapat perbedaan pendapat dan pemahaman guru terhadap model pembelajaran blended learning. Oleh karena itu diperlukan tinjauan terhadap persepsi guru mengenai model pembelajaran blended learning. Penelitian ini bertujuan untuk mengetahui bagaimana persepsi guru mengenai model pembelajaran blended learning yang diterapkan di SMK N 1 padang.

Defenisi Persepsi yaitu diartikan bagaimana seseorang atau individu memandang atau melihat sesuatu yang sama, namun mengartikan akan apa yang dilihatnya secara berbeda-beda [1]. Persepsi merupakan proses kognitif yang dialami oleh setiap orang di dalam memahami informasi tentang lingkungannya, baik lewat penglihatan, pendengaran, penghayatan, perasaan, dan penciuman [2]. Belajar merupakan suatu proses dari seseorang untuk mendapatkan suatu perubahan, yang merupakan hasil dari interaksinya dengan lingkungan [3]. Belajar merupakan sebuah upaya untuk menghasilkan dalam diri yang mempengaruhi seseorang yang menjadi lebih baik oleh pengalaman dan ilmu yang dimilikinya [4].

Model pembelajaran adalah rencana yang dilakukan untuk sebuah proses pembelajaran agar mencapai sebuah perubahan tertentu dalam tingkah laku siswa. Model pembelajaran adalah startegi pengajaran untuk disiapkan oleh guru agar tujuan pemmbelajaran tercapai [5]. Pembelajaran berbasis blended learning adalah pembelajaran yang mengkombinasi strategi penyampaikan pembelajaran menggunakan kegiatan tatap muka (offline) dan pembelajaran berbasis komputer (online), melalui internet dan mobile learning [6].

\section{METODE}

Jenis metode yang digunakan dalam penelitian ini adalah metode deskriptif kuantitatif. Pengumpulan data dilakukan dengan menyebarkan kuesioner/angket kepada responden, untuk mengetahui persepsi guru SMK Negeri 1 Padang yang melakukan pembelajaran blended learning. Populasi penelitian adalah guru di SMK Negeri 1 Padang yang berjumlah 90 orang. Metode pemilihan sampling dilakukan dengan simple 
random sampling (probability samping) sehingga diperoleh sampel sebanyak 47 orang dan untuk pengumpulan data digunakan kuesioner angket dengan Skala Likert.

Angket yang digunakan sudah di uji coba dan untuk mengetahui validitas digunakan program SPSS (statistik Package and socil science) 20.0. Kriteria dalam pengujian vadilitas tersebut adalah : Jika $r_{\text {hitung }}>r_{\text {tabel }}$ berarti valid Jika $r_{\text {hitung }}<r_{\text {tabel }}$ berarti tidak valid. Pada Tabel 1 dapat dilihat nilai $r_{\text {hitung }}$ dan $r_{\text {tabel }}$ dari 35 item pertanyaan pada angket yang digunakan.

Tabel 1. Perbandingan Nilai $r_{\text {hitung }}$ dan $r_{\text {tabel }}$ Dari Setiap Item Pada Angket yang Digunakan

\begin{tabular}{|c|c|c|c|}
\hline No & $r_{\text {hitung }}$ & $\mathrm{r}_{\text {tabel }}$ & Keterangan \\
\hline 1 & 0.372 & 0.361 & Valid \\
\hline 2 & 0.514 & 0.361 & Valid \\
\hline 3 & 0.604 & 0.361 & Valid \\
\hline 4 & 0.526 & 0.361 & Valid \\
\hline 5 & 0.514 & 0.361 & Valid \\
\hline 6 & 0.407 & 0.361 & Valid \\
\hline 7 & 0.596 & 0.361 & Valid \\
\hline 8 & 0.469 & 0.361 & Valid \\
\hline 9 & 0.604 & 0.361 & Valid \\
\hline 10 & 0.469 & 0.361 & Valid \\
\hline 11 & 0.574 & 0.361 & Valid \\
\hline 12 & 0.348 & 0.361 & Tidak valid \\
\hline 13 & 0.525 & 0.361 & Valid \\
\hline 14 & 0.475 & 0.361 & Valid \\
\hline 15 & 0.539 & 0.361 & Valid \\
\hline 16 & 0.526 & 0.361 & Valid \\
\hline 17 & 0.465 & 0.361 & Valid \\
\hline 18 & 0.604 & 0.361 & Valid \\
\hline 19 & 0.420 & 0.361 & Valid \\
\hline 20 & 0.555 & 0.361 & Valid \\
\hline 21 & 0.514 & 0.361 & Valid \\
\hline 22 & 0.500 & 0.361 & Valid \\
\hline 23 & 0.592 & 0.361 & Valid \\
\hline 24 & 0.626 & 0.361 & Valid \\
\hline 25 & 0.475 & 0.361 & Valid \\
\hline 26 & 0.422 & 0.361 & Valid \\
\hline 27 & 0.567 & 0.361 & Valid \\
\hline 28 & 0.527 & 0.361 & Valid \\
\hline 29 & 0.372 & 0.361 & Valid \\
\hline 30 & 0.600 & 0.361 & Valid \\
\hline 31 & 0.434 & 0.361 & Valid \\
\hline 32 & 0.383 & 0.361 & Valid \\
\hline 33 & 0.596 & 0.361 & Valid \\
\hline 34 & 0.604 & 0.361 & Valid \\
\hline 35 & 0.377 & 0.361 & Valid \\
\hline
\end{tabular}

Berdasarkan data pada tabel 1, maka dapat diambil kesimpulan bahwa pada uji validitas tidak semua pernyataan dalam angket valid. Pernyataan nomor 12 dinyatakan gugur karena $\mathrm{r}$ hitung < $\mathrm{r}$ tabel (tidak valid).

Setelah semua data terkumpul, maka selanjutnya melakukan analisa data. Hasil data yang sudah terkumpul akan di peroleh dan di analisis sesuai dengan tujuan pertanyaan penelitian. Proses analisis data hasil penelitian dilakukan sebagai berikut: 
Verifikasi data, memeriksa semua angket yang telah diisi repsonden, dicek kembali kelengkapannya, jika ada data yang kurang lengkap maka diminta kembali responden untuk melengkapinya. Kemudian melakukan tabulasi data yaitu meneliti semua jawaban yang telah diberikan responden serta memberikan skor masing-masing jawaban. Untuk jawaban sangat setuju $(S S)=5$, setuju $(S)=4$, ragu-ragu $(R R)=3$, tidak setuju $(S T)=2$. dan sangat tidak setuju (STS) $=1$. Menentukan skor masing-masing jawaban reponden berpedoman kepada persamaan (1).

$$
\mathrm{M}=\frac{\sum \mathrm{fx}}{\mathrm{N}}
$$

dimana;

M : rata-rata skor yang dicari

$\sum \mathrm{fx} \quad$ : jumlah skor keseluruhan

$\mathrm{N} \quad$ : jumlah responden

Menentukan kualitas dari persepsi guru terhadap pelaksanaan pembelajaran blended learning dengan menggunakan kriteria batas nyata skala likert dimana interprestasi tingkat capaian skor adalah seperti pada Tabel 2.

Tabel 2. Skor Kriteria Batas yang Digunakan

\begin{tabular}{|c|c|c|}
\hline No & Skor & Kategoru \\
\hline 1 & $4,6-5,0$ & Sangat baik \\
\hline 2 & $3,6-4,5$ & Baik \\
\hline 3 & $2,6-3,5$ & Cukup baik \\
\hline 4 & $1,6-2,5$ & Kurang baik \\
\hline 5 & $0,6-1,5$ & Tidak baik \\
\hline
\end{tabular}

\section{HASIL DAN PEMBAHASAN}

\section{Hasil}

Dari Tabel 3 dapat dilihat terdapatnya persepsi positif dari guru tentang model pembelajaran menggunakan model pembelajaran blended learning. Skor rata-rata tertinggi adalah model blended learning jelas untuk dipahami dengan baik dan detail oleh guru dengan skor rata-rata 4,72. Sedangkan skor rata-rata terendah yaitu model blended learning dapat digunakan untuk membantu penguasaan kompetensi teori pada siswa dengan skor rata-rata 4,19. 
Tabel 3. Persepsi Guru Tentang Model Pembelajaran Blended Learning.

\begin{tabular}{|c|c|c|c|c|c|c|c|c|c|c|c|c|c|c|c|}
\hline \multirow{3}{*}{ NO } & \multirow{3}{*}{ Perny ataan } & \multicolumn{10}{|c|}{ Alternatif Jawaban } & \multirow{2}{*}{\multicolumn{2}{|c|}{ Jumlah }} & \multirow{3}{*}{ Rata-Rata } & \multirow{3}{*}{ Keterangan } \\
\hline & & \multicolumn{2}{|c|}{ SS } & \multicolumn{2}{|c|}{ ST } & \multicolumn{2}{|c|}{ RG } & \multicolumn{2}{|c|}{$\mathrm{TS}$} & \multicolumn{2}{|c|}{ STS } & & & & \\
\hline & & F & $\mathrm{Fx}$ & $\mathrm{F}$ & Fx & F & Fx & F & Fx & F & Fx & $\mathrm{N}$ & $\mathrm{Fx}$ & & \\
\hline \multicolumn{16}{|c|}{ A. Model Pembelajaran Bleded learning. } \\
\hline 1 & $\begin{array}{l}\text { Model blended learning jelas untuk } \\
\text { dipahami dengan baik dan detail oleh } \\
\text { guru. }\end{array}$ & 34 & 170 & 13 & 52 & 0 & 0 & 0 & 0 & 0 & 0 & 47 & 222 & 4,72 & Sangat Baik \\
\hline 2 & $\begin{array}{l}\text { Karakteristik model blended learning } \\
\text { dalam perencanaan pembelajaran } \\
\text { sangat jelas. }\end{array}$ & 24 & 120 & 21 & 84 & 2 & 6 & 0 & 0 & 0 & 0 & 47 & 210 & 4,47 & Sangat Baik \\
\hline 3 & $\begin{array}{l}\text { Model blended learning sangat efektif } \\
\text { digunakan saat pandemi Covid-19 } \\
\text { untuk mencapai tujuan pembelajaraan. }\end{array}$ & 15 & 75 & 31 & 124 & 1 & 3 & 0 & 0 & 0 & 0 & 47 & 202 & 4,30 & Baik \\
\hline 4 & $\begin{array}{l}\text { Model blended learning dapat } \\
\text { digunakan untuk membantu } \\
\text { menuntaskan materi pelajaran y ang } \\
\text { memiliki cakup an materi luas. }\end{array}$ & 22 & 110 & 21 & 84 & 4 & 12 & 0 & 0 & 0 & 0 & 47 & 206 & 4,38 & Baik \\
\hline 5 & $\begin{array}{l}\text { Model blended learning sesuai dengan } \\
\text { gay a belajar siswa pada pandemi } \\
\text { Covid-19. }\end{array}$ & 20 & 100 & 18 & 72 & 9 & 27 & 0 & 0 & 0 & 0 & 47 & 199 & 4,23 & Baik \\
\hline 6 & $\begin{array}{l}\text { Model blended learning efektif dan } \\
\text { efisien untuk penguasaan kompetensi } \\
\text { teori sehingga melengkapi kegiatan } \\
\text { pembelajaran. }\end{array}$ & 18 & 90 & 23 & 92 & 6 & 18 & 0 & 0 & 0 & 0 & 47 & 200 & 4,26 & Baik \\
\hline 7 & $\begin{array}{l}\text { Model blended learning efektif dan } \\
\text { efisien untuk penguasaan kompetensi } \\
\text { praktikum sehingga melengkapi } \\
\text { kegiatan pembelajaran. }\end{array}$ & 20 & 100 & 18 & 72 & 9 & 27 & 0 & 0 & 0 & 0 & 47 & 199 & 4,23 & Baik \\
\hline 8 & $\begin{array}{l}\text { Model blended learning dapat } \\
\text { digunakan untuk membantu } \\
\text { penguasaan kompetensi teori pada } \\
\text { siswa. }\end{array}$ & 20 & 100 & 16 & 64 & 11 & 33 & 0 & 0 & 0 & 0 & 47 & 197 & 4,19 & Baik \\
\hline 9 & $\begin{array}{l}\text { Model blended learning dapat } \\
\text { digunakan untuk membantu } \\
\text { penguasaan kompetensi praktik pada } \\
\text { siswa. }\end{array}$ & 25 & 125 & 15 & 60 & 7 & 21 & 0 & 0 & 0 & 0 & 47 & 206 & 4,38 & Baik \\
\hline 10 & $\begin{array}{l}\text { Ketersediaan akses belajar mandiri } \\
\text { untuk mendukung pembelajaran } \\
\text { dengan model blended learning }\end{array}$ & 22 & 110 & 18 & 72 & 7 & 21 & 0 & 0 & 0 & 0 & 47 & 203 & 4,32 & Baik \\
\hline & & & & & Rata-r & & & & & & & & & 4,35 & Baik \\
\hline
\end{tabular}

Dilihat dari dari Tabel 4, dari pelaksanaan metode pembelajaran blended learning bahwa skor rata-rata tertinggi adalah Guru bertanya kepada siswa tentang materi sebelumnya dengan skor rata-rata 4,72. Sedangkan skor rata-rata terendah yaitu pada saat proses pembelajaran blended learning guru memberikan kesempatan berdiskusi tentang materi pembelajaran yang telah diberikan, skor rata-rata adalah 4,02. 
Tabel 4. Persepsi Guru Tentang Pelaksanaan Metode Pembelajaran Blended Learning.

\begin{tabular}{|c|c|c|c|c|c|c|c|c|c|c|c|c|c|c|c|}
\hline \multirow{3}{*}{ No } & \multirow[t]{3}{*}{ Pernyataan } & \multicolumn{10}{|c|}{ Alternatif Jawaban } & \multirow{2}{*}{\multicolumn{2}{|c|}{ Jumlah }} & \multirow{3}{*}{$\begin{array}{l}\text { Rata- } \\
\text { Rata }\end{array}$} & \multirow{3}{*}{ Keterangan } \\
\hline & & \multicolumn{2}{|c|}{ SS } & \multicolumn{2}{|c|}{ ST } & \multicolumn{2}{|c|}{ RG } & \multicolumn{2}{|c|}{ TS } & \multicolumn{2}{|c|}{ STS } & & & & \\
\hline & & $\mathrm{F}$ & $\mathrm{Fx}$ & $\mathrm{F}$ & Fx & $\mathrm{F}$ & Fx & $\mathrm{F}$ & $\mathrm{Fx}$ & $\mathrm{F}$ & Fx & $\mathrm{N}$ & Fx & & \\
\hline \multicolumn{16}{|c|}{ B. Metode Pembelajaran Blended learning. } \\
\hline 1 & $\begin{array}{l}\text { Guru menggunakan metode ceramah pada } \\
\text { saat pembelajaran blended learning. }\end{array}$ & 23 & 115 & 22 & 88 & 2 & 6 & 0 & 0 & 0 & 0 & 47 & 209 & 4,45 & Baik \\
\hline 2 & $\begin{array}{l}\text { Guru menjelaskan materi pada saat proses } \\
\text { belajar mengajar dengan menggunakan } \\
\text { pembelajaran blended learning. }\end{array}$ & 25 & 125 & 15 & 60 & 7 & 21 & 0 & 0 & 0 & 0 & 47 & 206 & 4,38 & Baik \\
\hline 3 & $\begin{array}{l}\text { Guru bertanya kepada siswa tentang materi } \\
\text { sebelumnya dengan menggunakan } \\
\text { pembelajaran blended learning. }\end{array}$ & 34 & 170 & 13 & 52 & 0 & 0 & 0 & 0 & 0 & 0 & 47 & 222 & 4,72 & Sangat Baik \\
\hline 4 & $\begin{array}{l}\text { Guru memberikan kesempatan siswa untuk } \\
\text { bertanya pada saat pembelajaran blended } \\
\text { learming. }\end{array}$ & 25 & 125 & 18 & 72 & 4 & 12 & 0 & 0 & 0 & 0 & 47 & 209 & 4,45 & Baik \\
\hline 5 & $\begin{array}{l}\text { Pada saat pembelajaran blended learning } \\
g \text { uru membahas pertanyaan yang telah } \\
\text { diberikan. }\end{array}$ & 27 & 135 & 17 & 68 & 3 & 9 & 0 & 0 & 0 & 0 & 47 & 212 & 4,51 & Baik \\
\hline 6 & $\begin{array}{l}\text { Guru memberikan tugas kepada siswa saat } \\
\text { pembelajaran blended learning. }\end{array}$ & 20 & 100 & 22 & 88 & 5 & 15 & 0 & 0 & 0 & 0 & 47 & 203 & 4,32 & Baik \\
\hline 7 & $\begin{array}{l}\text { Guru memberikan batas waktu pengumpulan } \\
\text { tugas pada proses pembelajaran blended } \\
\text { learning. }\end{array}$ & 19 & 95 & 19 & 76 & 9 & 27 & 0 & 0 & 0 & 0 & 47 & 198 & 4,21 & Baik \\
\hline 8 & $\begin{array}{l}\text { Pada proses pembelajaran blended learning } \\
\text { guru memberikan tugas dengan tujuan } \\
\text { mengumpulkan informasi tentang } \\
\text { pemahaman siswa untuk peningkatan hasil } \\
\text { belajar yang dicapai. }\end{array}$ & 17 & 85 & 24 & 96 & 6 & 18 & 0 & 0 & 0 & 0 & 47 & 199 & 4,23 & Baik \\
\hline 9 & $\begin{array}{l}\text { Pada saat proses pembelajaran blended } \\
\text { learning guru memberikan kesempatan } \\
\text { berdiskusi tentang materi pembelajaran yang } \\
\text { telah diberikan. }\end{array}$ & 14 & 70 & 20 & 80 & 13 & 39 & 0 & 0 & 0 & 0 & 47 & 189 & 4,02 & Baik \\
\hline 10 & $\begin{array}{l}\text { Pada saat proses pembelajaran blended } \\
\text { learning guru memberikan kesempatan pada } \\
\text { siswa untuk menghubungkan teori fakta di } \\
\text { lingkungan. }\end{array}$ & 21 & 105 & 18 & 72 & 8 & 24 & 0 & 0 & 0 & 0 & 47 & 201 & 4,28 & Baik \\
\hline 11 & $\begin{array}{l}\text { Pada saat proses pembelajaran blended } \\
\text { learning guru memberikan kesempatan } \\
\text { berdiskusi kepada siswa untuk meningkatan } \\
\text { pemahaman terhadap materi pelajaran. }\end{array}$ & 19 & 95 & 25 & 100 & 3 & 9 & 0 & 0 & 0 & 0 & 47 & 204 & 4,34 & Baik \\
\hline 12 & $\begin{array}{l}\text { Dengan menggunakan pembelajaran blended } \\
\text { learning praktikum tetap dilaksanakan saat } \\
\text { pandemi covid-19. }\end{array}$ & 20 & 100 & 21 & 84 & 6 & 18 & 0 & 0 & 0 & 0 & 47 & 202 & 4,30 & Baik \\
\hline 13 & $\begin{array}{l}\text { Dengan menggunakan pembelajaran blended } \\
\text { learning praktikum tetap dilaksanakan sesuai } \\
\text { jadwal yang sudah di tentukan pada saat } \\
\text { pandemi covid-19. }\end{array}$ & 22 & 110 & 19 & 76 & 6 & 18 & 0 & 0 & 0 & 0 & 47 & 204 & 4,34 & Baik \\
\hline 14 & $\begin{array}{l}\text { Praktikum dilaksanakan untuk meningkatan } \\
\text { pemahaman siswa pada materi pembelajaran. }\end{array}$ & 25 & 125 & 19 & 76 & 3 & 9 & 0 & 0 & 0 & 0 & 47 & 210 & 4,47 & Baik \\
\hline & & & & & a-Rata & & & & & & & & & 4,36 & Baik \\
\hline
\end{tabular}

Pada Tabel 5 dapat dilihat dimana dukungan terhadap bahan ajar cetak dalam pembelajaran dengan model blended learning memiliki skor yang paling tinggi, yaitu 4,70. Sedangkan skor rata-rata terendah adalah Media cetak dapat mendukung proses pembelajaran dengan menggunkanan model blended learning dengan skor rata-rata 4,30. 
Tabel 5. Persepsi Guru Tentang Media Pembelajaran Blended Learning.

\begin{tabular}{|c|c|c|c|c|c|c|c|c|c|c|c|c|c|c|c|}
\hline \multirow{3}{*}{ No } & \multirow{3}{*}{ Pernyataan } & \multicolumn{12}{|c|}{ Alternatif Jawaban } & \multirow{3}{*}{$\begin{array}{l}\text { Rata- } \\
\text { Rata }\end{array}$} & \multirow{3}{*}{ Keterangan } \\
\hline & & \multicolumn{2}{|c|}{ SS } & \multicolumn{2}{|c|}{ ST } & \multicolumn{2}{|c|}{ RG } & \multicolumn{2}{|c|}{ TS } & \multicolumn{2}{|c|}{ STS } & \multicolumn{2}{|c|}{ Jumlah } & & \\
\hline & & $\mathrm{F}$ & Fx & $\mathrm{F}$ & Fx & $\mathrm{F}$ & Fx & $\mathrm{F}$ & $\mathrm{Fx}$ & $\mathrm{F}$ & $\mathrm{Fx}$ & $\mathrm{N}$ & Fx & & \\
\hline \multicolumn{16}{|c|}{ C.Media Pembelajaran Blended learning. } \\
\hline 1 & $\begin{array}{l}\text { Dukungan bahan belajar cetak dalam } \\
\text { pembelajaran dengan model blended } \\
\text { learning telah tersedia. }\end{array}$ & 34 & 170 & 12 & 48 & 1 & 3 & 0 & 0 & 0 & 0 & 47 & 221 & 4,70 & Sangat Baik \\
\hline 2 & $\begin{array}{l}\text { Dukungan bahan belajar dalam pembelajaran } \\
\text { dengan menggunakan model blended } \\
\text { learning telah mencukupi. }\end{array}$ & 28 & 140 & 18 & 72 & 1 & 3 & 0 & 0 & 0 & 0 & 47 & 215 & 4,57 & Baik \\
\hline 3 & $\begin{array}{l}\text { Pada saat proses pembelajaran blended } \\
\text { learning terdapat penggunaan media cetak } \\
\text { pada proses belajar teori maupun praktikum. }\end{array}$ & 28 & 140 & 17 & 68 & 1 & 3 & 0 & 0 & 0 & 0 & 47 & 211 & 4,49 & Baik \\
\hline 4 & \begin{tabular}{|l|} 
Terdapat penggunaan jobsheet dan simulator \\
pada proses belajar praktikum saat \\
pembelajaran tatap muka dengan \\
menggunakan model blended learning.
\end{tabular} & 24 & 120 & 17 & 68 & 6 & 18 & 0 & 0 & 0 & 0 & 47 & 206 & 4,38 & Baik \\
\hline 5 & $\begin{array}{l}\text { Media cetak dapat mendukung proses } \\
\text { pembelajaran dengan menggunkanan model } \\
\text { blended learning. }\end{array}$ & 22 & 110 & 17 & 68 & 8 & 24 & 0 & 0 & 0 & 0 & 47 & 202 & 4,30 & Baik \\
\hline 6 & $\begin{array}{l}\text { Dukungan bahan belajar menggunakan media } \\
\text { teknologi pada pembelajaran dengan model } \\
\text { blended learning telah tersedia. }\end{array}$ & 25 & 125 & 22 & 88 & 0 & 0 & 0 & 0 & 0 & 0 & 47 & 213 & 4,53 & Baik \\
\hline 7 & $\begin{array}{l}\text { Dukungan bahan belajar menggunakan media } \\
\text { teknologi pada pembelajaran dengan } \\
\text { menggunakan model blended learning telah } \\
\text { mencukupi. }\end{array}$ & 28 & 140 & 15 & 60 & 4 & 12 & 0 & 0 & 0 & 0 & 47 & 212 & 4,51 & Baik \\
\hline 8 & $\begin{array}{l}\text { Terdapat penggunaan media teknologi } \\
\text { (komputer, laptop dan smartphone) pada } \\
\text { proses belajar teori saat pembelajaran } \\
\text { blended learning. }\end{array}$ & 29 & 145 & 16 & 64 & 2 & 6 & 0 & 0 & 0 & 0 & 47 & 215 & 4,57 & Baik \\
\hline 9 & $\begin{array}{l}\text { Terdapat penggunaan media teknologi } \\
\text { (komputer, laptop dan smartphone) pada } \\
\text { proses belajar praktikum saat pembelajaran } \\
\text { blended learning. }\end{array}$ & 26 & 130 & 18 & 72 & 3 & 9 & 0 & 0 & 0 & 0 & 47 & 211 & 4,49 & Baik \\
\hline 10 & $\begin{array}{l}\text { Media teknologi yang digunakan dalam } \\
\text { proses pembelajaran bisa mendukung proses } \\
\text { pembelajaran. }\end{array}$ & 31 & 155 & 15 & 60 & 1 & 3 & 0 & 0 & 0 & 0 & 47 & 218 & 4,64 & Sangat Baik \\
\hline & & & & & a-rata & & & & & & & & & 4,52 & Baik \\
\hline
\end{tabular}

Berdasarkan Tabel 3, Tabel 4 dan Tabel 5, maka skor rekapitulasi secara keseluruhan baik dari segi model, metode dan media pembelajaran Blended Learning dapat dilihat pada Tabel 6.

Tabel 6. Rekapitulasi Hasil

\begin{tabular}{|c|l|c|c|}
\hline No & Indikator & Rata-rata & Kriteria \\
\hline 1 & Model pembelajaran blended learning & 4,35 & Baik \\
\hline 2 & Metode pembelajaran blended learning & 4,36 & Baik \\
\hline 3 & Media pembelajaran blended learning & 4,52 & Baik \\
\hline \multicolumn{2}{|c}{ Rata-rata } & 4,41 & Baik \\
\hline
\end{tabular}

Hasil rata-rata dengan skor 4,41 dapat diartikan bahwasanya persepsi guru tentang pelaksanaan pembelajaran Blended Learning ditengah pandemi Covid-19 di SMK Negeri 1 Padang berada pada kategori baik.

\section{Pembahasan}

\section{Model Pembelajaran Blended Learning}

Skor rata-rata terendah yaitu, model blended learning dapat digunakan untuk membantu penguasaan kompetensi teori pada siswa dengan skor rata-rata 4,19. Kemungkinan penyebab rendahnya rata-rata skor pada pernyataan model blended 
learning dapat digunakan untuk membantu penguasaan kompetensi teori pada siswa mengakibatkan pada sulit diterapkan apabila sarana dan prasarana tidak mendukung, dan tidak meratanya fasilitas yang dimiliki oleh siswa. Solusi yang dapat dilakukan adalah seorang guru dapat berperan penting dalam merancang strategi pembelajaran yang akan dilakukan agar proses pembelajaran tercapai.

\section{Metode Pembelajaran Blended Learning}

Skor rata-rata terendah yaitu, pada saat proses pembelajaran blended learning guru memberikan kesempatan berdiskusi tentang materi pembelajaran yang telah diberikan dengan skor rata-rata 4,02. Kemungkinan penyebab rendahnya rata-rata skor pernyataan Pada saat proses pembelajaran blended learning guru memberikan kesempatan berdiskusi tentang materi pembelajaran yang telah diberikan, mengakibatkan kurangnya pemahaman siswa dalam materi yang telah disampaikan dan hanya mendapatkan informasi terbatas sehingga pada saat diskusi banyak siswa menyimpang dari materi tersebut sehingga tujuan pembelajaran tidak tercapai. Solusi yang dapat dilakukan adalah seorang guru dapat memberikan informasi materi dengan jelas agar siswa mudah memahami materi tersebut, dan seorang guru juga harus dapat memfokuskan para siswa pada materi yang sedang didiskusikan sehingga tujuan pembelajaran tercapai.

\section{Media Pembelajaran Blended Learning}

Skor rata-rata terendah yaitu media cetak dapat mendukung proses pembelajaran dengan menggunkanan model blended learning dengan skor rata-rata 4,30. Kemungkinan penyebab rendahnya rata-rata skor pernyataan media cetak dapat mendukung proses pembelajaran dengan menggunkanan model blended learning mengakibatkan media cetak memiliki kelemahan yaitu lambat dalam memberikan informasi sehingga siswa kurang dalam penguasan materi dan kurangnya minat baca pada siswa. Solusi yang dapat dilakukan adalah seorang guru dapat memberikan media cetak yang menarik sehingga siswa dapat memahami informasi yang diberikan.

Rekapitulasi Hasil

Persepsi guru tentang pelaksanaan pembelajaran blended learning ditengah pandemi covid-19 di SMK Negeri 1 Padang ditinjau dari model pembelajaran blended learning, metode pembelajaran blended learning, dan media pembelajaran blended learning. memiliki skor 4,41 dengan kategori baik. Skor rata-rata tertinggi tentang persepsi guru tentang pelaksanaan pembelajaran blended learning ditengah pandemi covid-19 di SMK Negeri 1 Padang terdapat media pembelajaran blended learning skor rata-rata 4,52 dengan kategori baik, sedangkan skor rata-rata terendah adalah model pembelajaran blended learning skor rata-rata 4,35 dengan kategori baik. Jadi persepsi guru tentang pelaksanaan pembelajaran blended learning ditengah pandemi covid-19 di SMK Negeri 1 Padang di tinjau dari model pembelajaran blended learning, metode pembelajaran blended learning, dan media pembelajaran blended learning. Bisa dikatakan sudah terlaksana dengan baik sesuai dengan angket yang diisi oleh guru di SMK Negeri 1 Padang. Untuk itu masih perlunya peningkatan dalam pelaksanaan pembelajaran blended learning yang dilakukan guru dalam mencapai kategori baik dan agar pelaksanaan pembelajaran blended learning terlaksana dengan semestinya. 


\section{KESIMPULAN DAN SARAN}

Pembelajaran blended learning ditengah pandemi covid-19 di SMKN 1 Padang sebagai berikut: Persepsi guru tentang pelaksanaan sistem pembelajaran blended learning di SMKN 1 Padang, dapat di tiunjau dari model pembelajaran blended learning, metode pembelajaran blended learning, dan media pembelajaran blended learning. Dengan ini bisa dikatakan sudah terlaksana dengan baik ini terbukti seusai dengan angket yang diisi oleh guru di SMKN 1 Padang. Dan pelaksanaan sistem pembelajaran blended learning dalam masa pandemi covid-19 sudah berjalan dengan baik, ini terbukti dari analisa data bahwa pelaksanaan pembelajaran blended learning yang dilihat dari model pembelajaran blended learning berada pada kategori Baik dengan skor rata-rata 4,35. Ini terbukti dari persepsi guru tentang pelaksanaan pembelajaran blended learning yang dilihat dari metode pembelajaran blended learning berada pada kategori baik dengan skor rata-rata 4,36. Ini terbukti dari persepsi guru tentang pelaksanaan pembelajaran blended learning yang dilihat dari media pembelajaran blended learning berada pada kategori baik dengan skor rata-rata 4,52.

Berdasarkan kesimpulan yang telah dikemukakan di atas, maka ada beberapa saran yang dapat di pertimbangan sebagai berikut: a) Pada indikator pertama yaitu yang mendapatkan skor terendah adalah model blended learning dapat digunakan untuk membantu penguasaan kompetensi teori pada siswa. Saran penulis adalah seorang guru dapat berperan penting dalam merancang strategi pembelajaran yang akan dilakukan agar proses pembelajaran tercapai. b) Pada indikator kedua pada saat proses pembelajaran blended learning guru memberikan kesempatan berdiskusi tentang materi pembelajaran yang telah diberikan. Saran penulis adalah seorang guru dapat memberikan informasi materi dengan jelas agar siswa mudah memahami materi tersebut, dan seorang guru juga harus dapat memfokuskan para siswa pada materi yang sedang didiskusikan sehingga tujuan pembelajaran tercapai. c) Pada indikator ketiga Media cetak dapat mendukung proses pembelajaran dengan menggunkanan model blended learning. Saran penulis adalah seorang guru dapat memberikan media cetak yang menarik sehingga siswa dapat memahami informasi yang diberikan.

\section{REFERENSI}

[1] R. A. Sari, "Pengaruh Teamwork dan Persepsi Pegawai tentang Pengawasan Pimpinan terhadap Motivasi Kerja Pegawai di Dinas Kependudukan dan Pencatatan Sipil Kabupaten Wonogiri,” 2019.

[2] M. Thoha, Perilaku Organisasi Konsep Dasar Dan Aplikasinnya. Jakarta: Rajawali Pers, 2015.

[3] Slameto, Belajar dan faktor-faktor yang mempengaruhinya. Jakarta: PT Rineka Cipta, 2013.

[4] R. Silaban, E. Alwi, and W. Wagino, "HUBUNGAN PERSEPSI SISWA TENTANG DISIPLIN SISWA DENGAN HASIL BELAJAR PADA MATA DIKLAT TEKNIK DASAR-DASAR OTOMOTIF SISWA KELAS X PROGRAM KEAHLIAN TEKNIK SEPEDA MOTOR SMK NEGERI 1 KOTO XI TARUSAN," Automot. Eng. Educ. J., vol. 1, no. 1, 2015.

[5] A. A. Wahab, Metode dan Model-Model Mengajar IPS. Bandung: Alfabeta, 2007. 
[6] E. Kuntarto and R. Asyhar, "Pengembangan Model Pembelajaran Blended Learning Pada Aspek Learning Design Dengan Platform Media Sosial Online Sebagai Pendukung Perkuliahan Mahasiswa," Repos. Unja, 2016.

[7] N. Sudjana, Dasar-dasar Proses\Belajar Mengajar. Bandung: Sinar Baru Algensindo, 2005.

[8] Y. Bilfaqih and M. Qomarudin N., Esensi Pengembangan Pembalajaran Daring. 2015.

[9] R. Nofianto, A. Andrizal, and W. Wagino, "Pengembangan Media Pembelajaran Interaktif untuk Mata Pelajaran Memperbaiki Sistem Starter dan Pengisian Berbasis Software Lectora Inspire pada Program Keahlian Teknik Kendaraan Ringan di Sekolah Menengah Kejuruan," Automot. Eng. Educ. J., vol. 1, no. 1, 2018. 